\title{
Regional assessment of bioeconomy options using the anaerobic biorefinery concept
}

\author{
María Natividad Pérez-Camacho PhD \\ Research Fellow, Centre for Advanced Sustainable Energy (CASE), Belfast, \\ UK; School of Chemistry and Chemical Engineering, Queen's University \\ Belfast, Belfast, UK (corresponding author: m.perezcamacho@qub.ac.uk)
}

\author{
Robin Curry FCIWM, FHEA \\ Lecturer, Centre for Advanced Sustainable Energy (CASE), Belfast, UK \\ School of Chemistry and Chemical Engineering, Queen's University Belfast, \\ Belfast, UK
}

One of the outputs on an ongoing programme of research into the bioeconomy concept in Northern Ireland was the publication of a 'Biogas Research Action Plan' in 2014, which included a 'Quantification of Feedstocks for Anaerobic Digestion' research project. This research quantified the feedstocks available for biogas production on a regional basis. The present research builds on and extends that previous work by applying the anaerobic biorefinery concept to the data for feedstocks for anaerobic digestion to include both biogas and digestate utilisation options. The assessment aims at evaluating the potential significance of anaerobic biorefineries on a regional basis, including types of feedstocks and uses for both biogas and digestate outputs. The use of the anaerobic biorefinery concept allows the evaluation of both biogas and digestate management pathways in an integrated way and can contribute to the development of a road map for a regional bioeconomy. The usefulness of the anaerobic biorefinery concept in informing regional and/or national policy and decision-making for the circular economy and the bioeconomy is evaluated, and recommendations made for future research priorities in this important research and policy area.

\section{Introduction}

A programme of research has been underway in Northern Ireland (NI) for a number of years with the aim of defining priorities for support to regional development, co-operation and knowledge transfer within the region in the field of production and use of biogas. One of the outputs of this research was the publication of a 'Quantification of Feedstocks for Anaerobic Digestion' report (Groom and Orozco, 2014: Appendix 3.1; see also 'Quantification of bioresource feedstocks for the development of a regional bioeconomy' by Curry et al., submitted to Waste and Resource Management). This research report quantified the feedstocks available for biogas production on a regional basis and provided estimates for potential biogas production, electrical and heat energy generation, and potential reductions in greenhouse gas (GHG) emissions from biogas utilisation. However, the research did not make any attempt to quantify the digestate outputs from the anaerobic digestion (AD) of these feedstocks or identify potential utilisation pathways. The present research builds on and extends this research by applying the anaerobic biorefinery concept to the data on feedstocks for AD to include both biogas and digestate utilisation options.

\subsection{Background}

$\mathrm{AD}$ is an established technology that involves the breakdown of organic materials by microorganisms under controlled conditions in the absence of oxygen. The products of $\mathrm{AD}$ are biogas and digestate. Biogas typically consists of 55-70\% methane $\left(\mathrm{CH}_{4}\right), 45-30 \%$ carbon dioxide $\left(\mathrm{CO}_{2}\right)$ and some minor constituents, such as hydrogen sulfide $\left(\mathrm{H}_{2} \mathrm{~S}\right)$ and water
(Smyth et al., 2010). Methane energy in the biogas can be combusted as a fuel and is commonly used for electricity generation and combined heat and power (CHP) generation. Digestate, which consists of a suspended solid fraction and the other liquid fraction containing soluble nutrients, is the material that remains at the end of the AD process. Digestate can be used as an organic fertiliser and is reported to be more suitable than raw agricultural wastes (e.g. slurry, manure) for fertiliser use (Monson et al., 2007). A particularly active area for research is approaches to optimise the process to increase biogas yield and to look for economical uses for the digestate outputs (Smyth et al., 2009).

One interesting approach is to place AD within the context of the anaerobic biorefinery, to allow an integrated approach that maximises synergies between technologies and processes (Sawatdeenarunat et al., 2016). The use of the anaerobic biorefinery concept allows the evaluation of both energy (electricity and heat) and chemical/material/nutrient management pathways in an integrated way and can contribute to the development of a road map for a regional bioeconomy (Vazquez-Rowe et al., 2015). A schematic diagram of the anaerobic biorefinery is shown in Figure 1 (adapted from Sawatdeenarunat et al. (2016)).

\subsection{Aims and objectives}

The overall aim of this research is to build on and extend the outputs of the regional 'Quantification of Feedstocks for Anaerobic Digestion' report through the application of the anaerobic biorefinery concept to both biogas and digestate 


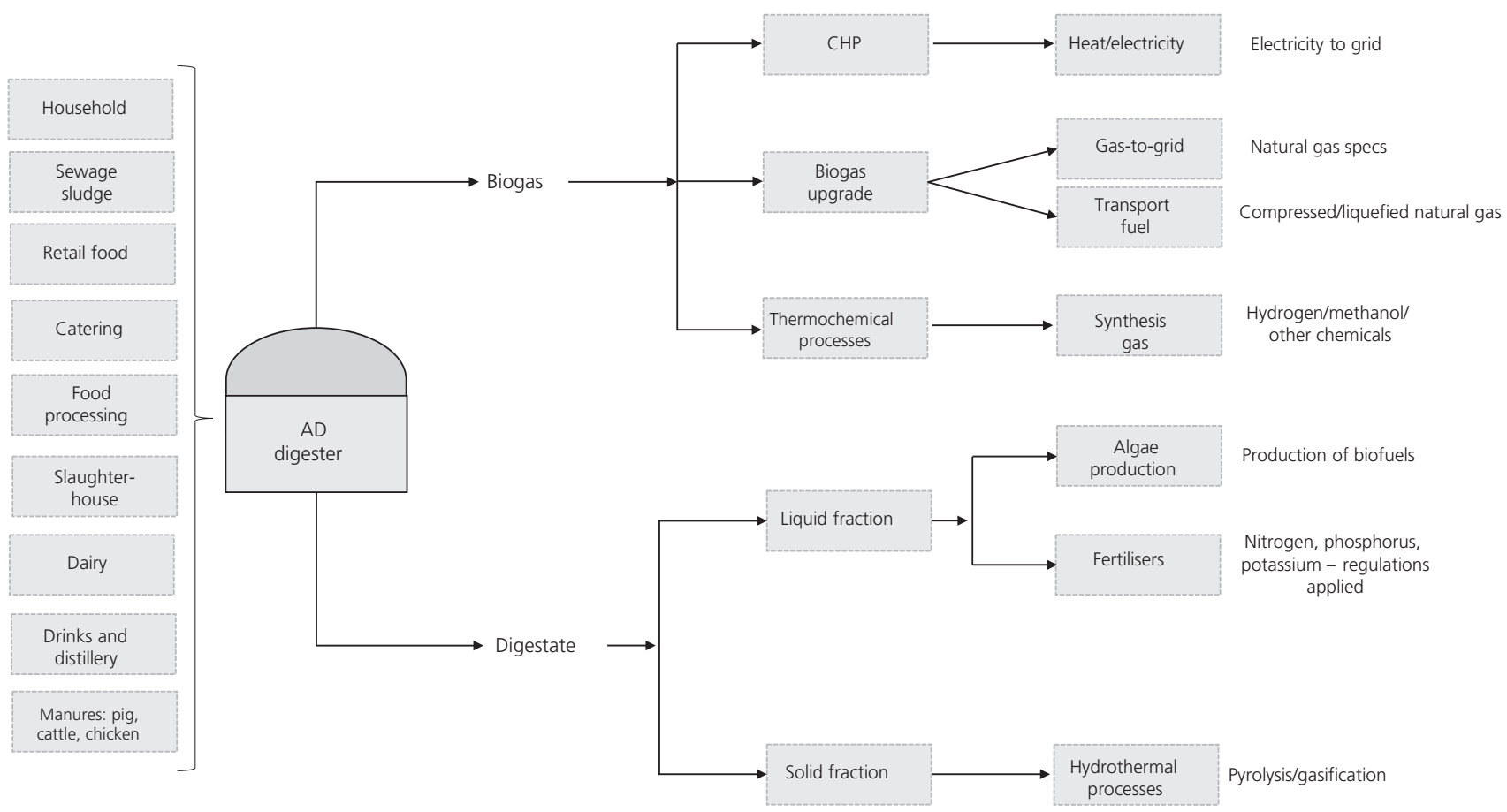

Figure 1. Schematic diagram of large-scale anaerobic biorefinery for production of biofuels and bio-based products (adapted from Sawatdeenarunat et al. (2016))

outputs from the AD process. The following underlying objectives underpin this aim

- to identify potential biogas and digestate production and utilisation pathways using the anaerobic biorefinery concept

- to contribute to the development of a road map for a regional bioeconomy

to gain an understanding of the usefulness of the anaerobic biorefinery concept in informing regional and/or national policy and decision-making for the circular economy and the bioeconomy

- to make recommendations for future research priorities in this important research and policy area.

\section{Methodology}

Data from the 'Quantification of Feedstocks for Anaerobic Digestion' research were used to evaluate the potential amounts of biogas and digestate that can be produced from organic wastes on a regional basis. This was followed by an evaluation of a selection of utilisation pathways for both biogas and digestate. Biogas and digestate were explored using the anaerobic biorefinery concept, for the following utilisation options

\section{- biogas (non-CHP)}

digestate as fertiliser digestate use for algae production

digestate use in hydrothermal processes (gasification/pyrolysis).

This study focused on the uses of digestate after dewatering for both the liquid and solid components. The liquid fraction of the digestate, which is the primary component, can be used as a fertiliser and for algae production (Xia and Murphy, 2016), while the solid fraction can be used in hydrothermal processes such as pyrolysis and gasification (Monlau et al., 2016).

It is acknowledged that a wide range of products can be manufactured in a biorefinery that are not included in this analysis (e.g. high-value products such as volatile fatty acids, polyhydroxyalkanoates/polyhydroxybutyrate polymers and surfactants (Sawatdeenarunat et al., 2016)). As such, this analysis represents a 'snap-shot' of the many potential production and utilisation pathways and this limitation is addressed in the conclusions and recommendations for future research priorities.

\section{Potential feedstocks for AD: initial data}

The 'Quantification of Feedstocks for Anaerobic Digestion' research estimated the potential feedstocks for AD as organic biodegradable materials from three main sectors: agriculture, 
Table 1. Summary of NI organic waste produced

\begin{tabular}{|lc|} 
Waste origin & $\begin{array}{c}\text { Waste amount } \\
\text { produced: } t / \text { year }\end{array}$ \\
\hline Municipal and commercial waste & 484000 \\
Manures & 10.8 million \\
Crops (grass silage) & 1.94 million \\
Total & 13.2 million
\end{tabular}

municipal, and commercial and industrial. The agriculture sector comprises the production of crops, grass silage and sugar beet; with residues such as wheat straw. The most commonly available source in NI is the production of manures from cattle, pig and poultry farms. The municipal sector comprises household, canteen and sewage sludge wastes, while the commercial and industrial sector comprises wastes produced from fruit and vegetable companies, industrial factories, supermarkets, tanneries, food processing companies, catering, dairy, fish processing, slaughterhouses and food scraps factories. The research estimated an average of $484000 \mathrm{t}$ of municipal and commercial and industrial waste produced, while manure production is $10.8 \mathrm{Mt} /$ year. Crops, basically grass silage, is reported to be $1.94 \mathrm{Mt} /$ year. Thus, the total estimated potential feedstocks for $\mathrm{AD}$ is $13.2 \mathrm{Mt} / \mathrm{year}$ in NI (Curry et al., submitted; Groom and Orozco, 2014). It should be noted that estimates of feedstock quantities are derived from the regional quantification of feedstocks research project, which used a methodology set out by Slade et al. (2011), who described how biomass potential estimates are most often discussed in terms of a 'hierarchy of opportunity': theoretical, technical, economic and realistic. This research used the theoretical estimates of the organic resources generated and potentially available, and these quantities were used to enable alignment of the regional biorefinery evaluation with the regional feedstocks project. It is acknowledged that technical and economic issues may impose limitations on the total quantities of feedstocks that can realistically be made available for AD. The main figures from the 'Quantification of Feedstocks for Anaerobic Digestion' research (Curry et al., submitted; Groom and Orozco, 2014) are summarised in Table 1.

\section{Potential utilisation pathways for AD outputs: the anaerobic biorefinery}

\subsection{Biogas (non-CHP)}

Biogas has traditionally been considered to be the main product in the AD of organic residues (AEBIOM, 2009). Its most common use is in a biogas engine for the production of electricity and heat (Holm-Nielsen et al., 2009). Usually, industrial plants producing biogas are able to use part of the produced electricity for self-consumption and feed the rest of the production into the national electricity grid. However, the biogas can also be upgraded to natural gas quality and be used as biomethane as part of a wider bioenergy system (Murphy et al., 2014), or utilised for producing energy and chemicals within the anaerobic biorefinery concept (Cherubini, 2010).

If the aim is the production of biomethane, the biogas from AD must first be upgraded and further purified after the initial hydrogen sulfide removal stage. A range of technologies exists to do this, including water scrubbing, pressure swing adsorption and amine scrubbing. The most extensively used process for large-scale systems ( $>100 \mathrm{Nm}^{3}$ biogas per hour) is water scrubbing (Yliopisto, 2013).

Standards have been developed for the upgrading of biogas to allow it to be used as a substitute for natural gas (Bright et al., 2011). This option is gaining the interest of policymakers in traditional gas markets such as the UK, the Netherlands and Germany. Targets for its production are being included in some national renewable plans; furthermore, biomethane is also attractive to gas companies as a low-carbon dioxide energy source (AEBIOM, 2009).

Other uses of biogas include the production of synthesis gas (syngas), which is a mixture containing varying amounts of carbon oxide and hydrogen. It can be produced by reforming hydrocarbon-containing streams such as methane or biogas, or through gasification of coal. The main processes for the production of syngas from methane are steam reforming, dry reforming (DRM) and partial oxidation of methane, or a combination of these. These processes are based on one or more chemical reactions that are either endothermic or exothermic. Achieving an appropriate balance of these reactions can result in processes that require little added energy (Pérez-Camacho et al., 2015). Synthesis gas can be used as a fuel in similar ways to methane, such as combustion in a gas turbine or an internal combustion engine. In DRM, two of the most abundant carbon-containing GHGs, methane and carbon dioxide, react to form more valuable products - that is, carbon monoxide $(\mathrm{CO})$ and hydrogen $\left(\mathrm{H}_{2}\right)\left(\mathrm{CH}_{4}+\mathrm{CO}_{2} \leftrightarrow 2 \mathrm{CO}+2 \mathrm{H}_{2}\right)$. From an industrial point of view, DRM also satisfies the requirements of many synthesis processes generating oxygenated compounds and liquid hydrocarbons (Fischer-Tropsch synthesis) from syngas - that is, a syngas with a ratio of hydrogen/carbon monoxide close to 1 (Choudhary et al., 2006).

The estimation of biogas production by Curry et al. (submitted) quantified ca. 491 million $\mathrm{m}^{3}$ of biogas produced per year from $\mathrm{AD}$ in NI. It has been assumed that half of this amount is used for the upgrading of biogas to biomethane and half for synthesis gas production. Based on this assumption, the amount of biomethane produced would potentially be $120 \cdot 3$ million $\mathrm{m}^{3}$ per year, which corresponds to 132 million litres of diesel (IEA, 2015), while the syngas to be produced would be 390 million $\mathrm{m}^{3}$ per year, based on a conversion 
Table 2. Biogas non-CHP utilisation options

Biogas as a feedstock $=\mathbf{4 9 1}$ million $\mathbf{m}^{\mathbf{3}}$ per year
$\begin{aligned} & \text { Biomethane production (million } \mathrm{m}^{3} \text { per year) as } \\ & 98 \% \mathrm{v} / \mathrm{v} \text { purity } \\ & \text { Synthesis gas production (million } \mathrm{m}^{3} \text { per year) }\end{aligned} \quad 390 \cdot 1^{\text {a }}$

${ }^{\mathrm{a}}$ For a conversion factor of biogas to syngas of $70 \%$ (Pérez-Camacho et al., 2014)

factor of biogas to syngas of 70\% (Pérez-Camacho et al., 2014). These data are summarised in Table 2.

\subsection{Digestate}

Digestate is the general term used to designate the material left after the production of biogas from the AD process. It is composed of undigested solids and the liquid fraction of the digested feedstock. Between 90 and $95 \%$ of the feed to the digester will remain as digestate (Tampio et al., 2016; WRAP, 2012). Depending on the feedstock, the percentage of dry matter will vary. The reported values of dry solids can vary from $4 \cdot 33 \%$ for food-based digestate to $8 \cdot 22 \%$ for manurebased digestate (WRAP, 2011), while the assumed value for grass silage digestate was 6.6\% (Drosg et al., 2015).

Research has shown that the AD process consumes relatively few nutrients and enhances the availability of nutrients such as nitrogen, phosphorous and potassium (Ayala-Parra et al., 2017; Svehla et al., 2017). Results from work carried out at AFBI Research Centre in NI (Frost and Gilkinson, 2011) demonstrated that the fertiliser value of digested cattle slurry was increased by about $15 \%$, and this is supported by other researchers who have demonstrated similar improvements (Matsunaka et al., 2006; Tani et al., 2006).

The further refining of the digestate through different treatments and technologies is called digestate processing. The most usual process, due to its simplicity and low cost, is the separation of the digestate into liquid and solid fractions. For the separation, decanter centrifuges and screw press separators are the most commonly used technology although there is a range of other processes/technologies available (at varying levels of technology readiness), all having the same broad aims: volume reduction and separation of the nutrient and fibres with the higher value from the water contained in the digestate (Al Seadi et al., 2013; Flotats et al., 2011).

Table 3 provides estimates for the regional production of digestate per year in NI. Assuming 12 different streams for the waste produced in NI - household, sewage sludge, retail food, catering, food processing, slaughterhouse, dairy, drinks and distillery, dairy manure, pig manure, chicken manure and crops (Curry et al., submitted; Groom and Orozco, 2014) - the amount of digestate produced per stream is calculated assuming that all the waste produced is anaerobically digested, with the resulting digestate being $90 \%$ of the initial fed to the reactors (Tampio et al., 2016; WRAP, 2012). Then, the percentage of dry solids has been applied to each stream. This percentage will vary depending on the origin of the feedstock: from $4.33 \%$ for foodbased digestate to $8 \cdot 22 \%$ for manure-based digestate (WRAP, 2011) and 6.6\% for grass silage digestate (Drosg et al., 2015), obtaining the values of solid and liquid fractions for each stream and the total as a sum of them.

Using this methodology, estimation results are $0.9 \mathrm{Mt} /$ year for the solid fraction and $11 \mathrm{Mt} / \mathrm{year}$ for the liquid fraction of the digestate. These figures are set out in Table 3.

The separation of liquid and solid fractions of the digestate can be done utilising a decanter centrifuge-type equipment (Flotats et al., 2011; Tampio et al., 2016), while the liquid fraction can be further treated to produce fertiliser products.

\subsubsection{Digestate as a fertiliser}

The liquid fraction of the digestate can be upgraded to enhance its use as a fertiliser. A range of processes/technologies is available to do this, including ammonia stripping, evaporation, struvite precipitation, membrane separation or a combination of them (Antonini et al., 2011; Boehler et al., 2015; Bonmatí and Flotats, 2003a, 2003b; Chiumenti et al., 2013).

Tampio et al. (2016) compared the potential of four digestate liquid treatment processes in a theoretical AD plant using food waste to produce fertilisers with low water content and high nutrient value, and provided estimates of the conversion efficiency of each.

The four options for producing fertilisers are described below together with their production efficiencies (Tampio et al., 2016).

- S1, consisting of the stripping of the ammonia contained in the liquid digestate with sulfuric acid producing ammonium sulfate and stripping residue. Efficiency of fertiliser production: $79 \mathrm{wt} \%$.

- S2, consisting of the combination of ammonia stripping with reverse osmosis (RO) to produce ammonium sulfate. Efficiency of fertiliser production: $26 \mathrm{wt} \%$.

- S3, combining evaporation with RO where the liquid digestate is concentrated in the evaporation and then undergoes an RO process to concentrate the product further. Efficiency of fertiliser production: $16 \mathrm{wt} \%$.

- S4, combining stripping, evaporation and RO. Efficiency of fertiliser production: $20 \mathrm{wt} \%$.

Utilising these efficiency values, the potential production of fertiliser from the liquid fraction of the digestate has been 
Table 3. Production of digestate per year in NI

\begin{tabular}{|c|c|c|c|c|c|}
\hline Waste category & $\begin{array}{l}\text { Waste amount: } \\
\text { t/year }\end{array}$ & $\begin{array}{l}\text { Digestate from each } \\
\text { source of waste: tyear }\end{array}$ & Dry solids: \% & $\begin{array}{c}\text { Solid fraction: } \\
\text { t/year }\end{array}$ & $\begin{array}{c}\text { Liquid fraction: } \\
\text { t/year }\end{array}$ \\
\hline Household & $244043 \cdot 67$ & $219639 \cdot 30$ & $4 \cdot 33$ & $9510 \cdot 38$ & 210128.92 \\
\hline Sewage sludge & $38566 \cdot 667$ & 34710 & $4 \cdot 33$ & $1502 \cdot 94$ & 33207.06 \\
\hline Retail food & 35700 & 32130 & $4 \cdot 33$ & $1391 \cdot 23$ & $30738 \cdot 77$ \\
\hline Catering & 4140 & 3726 & $4 \cdot 33$ & $161 \cdot 34$ & 3564.66 \\
\hline Food processing & 26000 & 23400 & $4 \cdot 33$ & $1013 \cdot 22$ & $22386 \cdot 78$ \\
\hline Slaughterhouse & 17823 & 160407 & $4 \cdot 33$ & $6945 \cdot 62$ & $153461 \cdot 38$ \\
\hline Dairy & 13200 & 11880 & $4 \cdot 33$ & $514 \cdot 40$ & $11365 \cdot 60$ \\
\hline Drinks and distillery & 12000 & 10800 & $4 \cdot 33$ & $467 \cdot 64$ & $10332 \cdot 36$ \\
\hline Dairy cattle manure & 10000000 & 9000000 & $8 \cdot 22$ & 739800 & 8260200 \\
\hline Pig manure & 500000 & 450000 & $8 \cdot 22$ & 36990 & 413010 \\
\hline Chicken manure & 300000 & 270000 & $8 \cdot 22$ & 22194 & 247806 \\
\hline Crops (grass silage) & $1937170 \cdot 12$ & $1743453 \cdot 10$ & $6 \cdot 6$ & $115067 \cdot 90$ & $1628385 \cdot 20$ \\
\hline Total & & & & 935558.68 & $11024586 \cdot 72$ \\
\hline Millions & & & & 0.936 & 11.02 \\
\hline
\end{tabular}

Table 4. Fertiliser production potential from the liquid fraction of the digestate

\begin{tabular}{|c|c|c|c|}
\hline \multicolumn{2}{|c|}{$\begin{array}{l}\text { Feedstock for fertilisers (liquid fraction of the } \\
\text { digestate) }=5 \cdot 5 \mathrm{Mt} / \text { year }\end{array}$} & \multicolumn{2}{|c|}{ Estimation } \\
\hline Fertiliser production technology & wt $\%$ of fertiliser ${ }^{a}$ & Fertiliser produced: t/year & Fertiliser produced: Mt/year \\
\hline S1 (stripping) & 79 & $4354711 \cdot 76$ & $4 \cdot 35$ \\
\hline $\mathrm{S} 2$ (stripping + RO) & 26 & $1433196 \cdot 27$ & $1 \cdot 43$ \\
\hline S3 (evaporation + RO & 16 & 881966.94 & $0 \cdot 88$ \\
\hline S4 (evaporation + stripping + RO) & 20 & $1102458 \cdot 67$ & $1 \cdot 10$ \\
\hline
\end{tabular}

${ }^{a}$ Using efficiencies from Tampio et al. (2016)

estimated based on the assumption that $50 \%$ of the total liquid digestate $(5.5 \mathrm{Mt} /$ year) produced will be used in this process. The results are set out in Table 4 .

In order to be no longer classified as a waste, fertilisers produced from digestate must comply with the biofertiliser certification scheme, which provides assurance to consumers, farmers, food producers and other retailers about the safety of fertilisers from digestate to human, animal and plant health (EA and WRAP, 2009). Digestate that meets the criteria set out by the quality protocol and standard PAS 110 or any other approved standard is then known as biofertiliser (EA and WRAP, 2009; WRAP, 2014).

\subsubsection{Digestate use for algae production}

There is a wide range of technologies and processes for the recycling of nutrients from waste water using algae (Markou and Georgakakis, 2011; Prajapati et al., 2014; Rawat et al., 2011). Algae have the ability to grow and extract nutrients from waste, which increases the feasibility and economic viability of biofuel based on algae streams. There are studies on $\mathrm{AD}$ of manure and industrial liquid effluents for the production of biomass algae where the algae production is enhanced by adding the liquid fraction of the digestate to them. One example is research performed by Wang et al. (2010) whose cultivation of Chlorella sp. was carried out in diluted dairy manure by way of $\mathrm{AD}$. The liquid fraction of the digestate from AD is rich in nutrients, which can be used for cultivation of algae. It is also possible to use the algal digestion for biogas production with subsequent utilisation of the liquid digestate as a nutrient source for more algae cultivation. There are studies where a process using liquid digestate from algae cultivation was used as a medium for the growth of more algae (Prajapati et al., 2014).

Another promising area of research is bioproducts derived from microalgae; however, commercial applications have yet to be developed due to the current cultivation costs. If liquid digestate treatment and microalgae cultivation are combined, a significant reduction in the nutrient cost could be achieved (Xia and Murphy, 2016). Research done by Xia and Murphy (2016) has demonstrated how $1 \mathrm{~m}^{3}$ of liquid digestate could be used as the nutrient source of microalgae cultivation, producing $14.6 \mathrm{~kg}$ volatile solids (VS) of microalgae (Xia and Murphy, 2016). This value has been used in the authors' 
Table 5. Algae and biodiesel production from liquid digestate

$\begin{array}{ll}\text { Liquid digestate as a feedstock = } 5.5 & \mathbf{M t} / \text { year } \\ \text { Algae production (Mt of VS of microalgae per year) } & 80 \cdot 3 \\ \text { Biodiesel production (million } \text { m }^{3} \text { per year) } & 53 \cdot 6\end{array}$

aUsing microalgae yield from Xia and Murphy (2016)

bUsing yield from the literature (Gnansounou and Kenthorai Raman, 2016)

calculation for the estimation of algae that could be produced from liquid digestate within the anaerobic biorefinery. This would potentially yield around $80 \mathrm{Mt}$ of VS of microalgae produced per year based on the use of $5.5 \mathrm{Mt}$ of liquid digestate for this, as set out in Table 5 .

The biofuel produced from algae is classified as a third generation biofuel and is promoted as a renewable biofuel with the potential to displace petroleum-derived transport fuels without adversely affecting the supply of food and other crop products (Piloto-Rodríguez et al., 2017). In addition, algae are a source for not only biofuels but also other bioproducts (Sawatdeenarunat et al., 2016; Xia and Murphy, 2016). For the purposes of this study, the estimation of how much biodiesel could be produced from the microalgae previously produced using liquid digestate as a nutrient source was based on yields from Gnansounou and Kenthorai Raman (2016) and Xia and Murphy (2016). These results are set out in Table 5.

\subsubsection{Digestate for hydrothermal processes (gasification/pyrolysis)}

The solid fraction of the digestate is estimated to be between 4 and $8 \%$ of the total digestate produced (Drosg et al., 2015; WRAP, 2011) and although a smaller proportion than the liquid, it is a potentially valuable product. One example of this is its use in gasification/pyrolysis to manufacture a wide range of products such as synthesis gas (a mixture of hydrogen and carbon monoxide), bio-oils and biochar (Monlau et al., 2016).

Monlau et al. $(2015,2016)$ coupled pyrolysis with AD in an anaerobic biorefinery, and provided estimates of the quantities of biochar, bio-oil and syngas that could be produced. The estimates used in this research are based on their yield factors.

Pyrolysis is the direct thermal decomposition of biomass in the absence of oxygen and at $400-800^{\circ} \mathrm{C}$ (Gold and Seuring, 2011). The products, syngas, bio-oil and biochar and their relative proportions will depend on the pyrolysis method utilised and the type of biomass and the reaction parameters. In general, the yields are $40-65 \mathrm{wt} \%$ of bio-oil, $10-20 \%$ of biochar and $10-30 \%$ of syngas (Uslu et al., 2008). The data used for the calculations (Monlau et al., 2016) are covered by these ranges (Table 6).

Additionally, the solid fraction of the digestate can, at a further stage, also be used as a fertiliser (Deal et al., 2012). Through the pyrolysis process, biochar is produced. Biochar is a mixture of organic compounds also called 'black carbon' biomass with soil amendment properties. This converts the biochar into a carbon-sequestration product, contributing to global warming mitigation (Dias et al., 2010; Gold and Seuring, 2011; He et al., 2017).

Biochar can be used as an alternative to liquid digestate as a soil amendment, and its importance is related to its potential carbon-sequestration ability coupled with the provision of valuable nutrients (nitrogen, phosphorus). Some studies have focused on the combination of AD and pyrolysis (Monlau et al., 2015), while others (Monlau et al., 2016) have focused on the replacement of solid digestate for soils by biochar due to the similar or even better effects on soil quality. Similar biochar yields to the ones used for the authors' calculation (Table 6) have been found by Inyang et al., (2010), Stefaniuk and Oleszczuk (2015) and Yao et al. (2011). Recent publications (Monlau et al., 2016) have shown a 34\% yield of biochar from solid digestate and this is the yield factor used to estimate the production from the NI feedstock data.

It is also possible to combine $\mathrm{AD}$ with gasification. Gasification is the thermochemical conversion process where carbon-based materials at high temperature $\left(800-1200^{\circ} \mathrm{C}\right)$ react in an environment with a limited amount of oxygen, air

Table 6. Product estimation potential from the pyrolysis of the solid fraction of the digestate

\begin{tabular}{|c|c|c|c|}
\hline \multicolumn{2}{|c|}{$\begin{array}{l}\text { Feedstock for pyrolysis (solid fraction of } \\
\text { the digestate) }=820000 \mathrm{t} / \text { year }\end{array}$} & \multicolumn{2}{|c|}{ Estimation } \\
\hline \multicolumn{2}{|c|}{ wt $\%$ averages for each product ${ }^{a}$} & Products: t/year & Products: Mt/year \\
\hline Biochar & $34 \%$ & 318089.95 & 0.318 \\
\hline Bio-oil & $53 \cdot 50 \%$ & $500523 \cdot 89$ & 0.500 \\
\hline Syngas & $12 \cdot 50 \%$ & 116944.84 & $0 \cdot 116$ \\
\hline
\end{tabular}

aMonlau et al. (2016) 


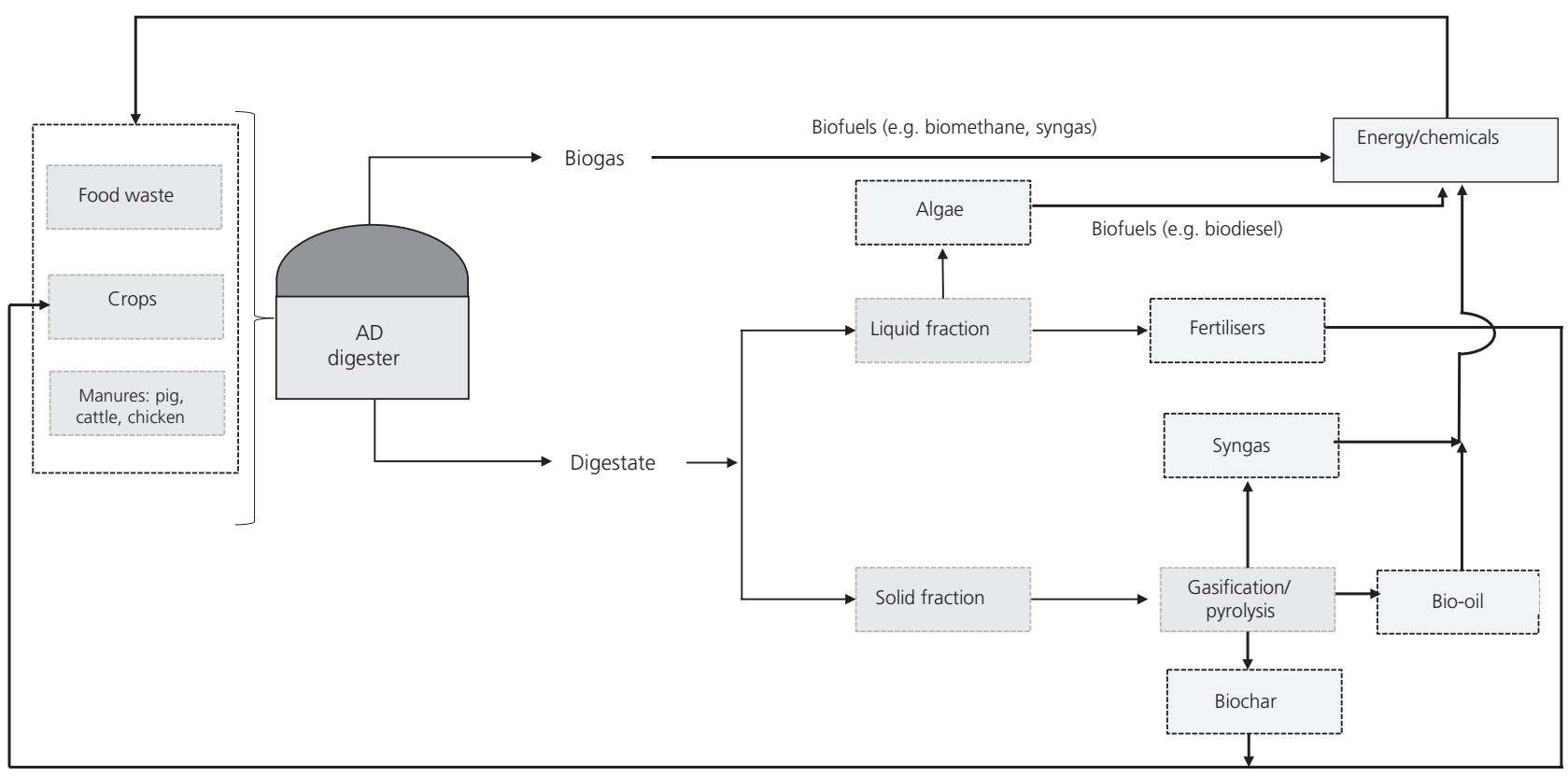

Figure 2. Schematic diagram of the proposed anaerobic biorefinery

and/or steam. The product is synthesis gas and a solid carbonrich material also called biochar. AD and gasification processes have the capacity to adapt their feedstocks and operational characteristics, which can lead to the manufacture of by-products with a wide range of physicochemical characteristics (Kataki et al., 2017).

Based on the above review of potential processing options and products, the following product options were selected for the estimation of product quantities from hydrothermal processes

biochar

- bio-oil

- syngas.

The results for the estimation of the products from the pyrolysis of the solid fraction of the digestate are presented in Table 6. The authors' results give an estimation of production as $0.318 \mathrm{Mt} /$ year of biochar, $0.500 \mathrm{Mt} /$ year of bio-oil and $0 \cdot 116 \mathrm{Mt} /$ year of syngas.

\section{Conclusions}

Using the data from the 'Quantification of Feedstocks for Anaerobic Digestion' research, the estimation of biogas and digestate production was explored using the concept of anaerobic biorefinery. The overall aim of this research was to apply the anaerobic biorefinery concept to the outputs of the regional 'Quantification of Feedstocks for Anaerobic Digestion' research estimates, with the following underlying objectives

- to identify potential biogas and digestate production and utilisation pathways using the anaerobic biorefinery concept

- to contribute to the development of a road map for a regional bioeconomy

- to gain an understanding of the usefulness of the anaerobic biorefinery concept in informing regional and/or national policy and decision-making for the circular economy and the bioeconomy

- to make recommendations for future research priorities in this important policy area.

The use of the anaerobic biorefinery concept has facilitated the identification of potential biogas and digestate production and utilisation pathways that have the potential to provide synergies and optimise the use of all of the outputs of AD. The use of yield factors from the literature has enabled estimates to be made of the potential quantities of product/material from each option; and although it must be emphasised that these are early estimates, they do provide a starting point for the development of a road map for a regional bioeconomy. As such, the authors conclude that the application of the anaerobic biorefinery concept is a useful model for informing regional and/or national policy and decision-making in the circular economy 
and the bioeconomy. In this research paper, the authors presented a possible application of the anaerobic biorefinery concept for NI that had potential organic material feedstocks for AD previously estimated. Figure 2 presents a schematic diagram of the proposed application of the anaerobic biorefinery for NI. The authors believe that this identifies a number of interesting and important priorities for an ongoing research to contribute to the further development and implementation of the bioeconomy concept. They would identify as a limitation of the research that it provides only a 'snap-shot' of the many potential production and utilisation pathways and this is addressed in future research priorities below.

\section{Recommendations for further research}

The authors would highlight the following areas as priorities for future research

- further development of the anaerobic biorefinery concept

- further analysis using as full a range of potential production and utilisation pathways as possible

- identification of potential synergies with other input processes for the bioeconomy, including gasification, fermentation and hydrodeoxygenation.

The authors hope that the issues identified and discussed in this paper can provide insights for other researchers and help set out the priorities for research to support this important policy area.

\section{Acknowledgements}

The research was funded by the Centre for Advanced Sustainable Energy (CASE) and carried out as part of the 'Biogas to Biorefinery' project. CASE is funded through the Invest NI Northern Ireland Competence Centre programme, which bridges the gap between industry research needs and academic research offerings.

\section{REFERENCES}

AEBIOM (European Biomass Association) (2009) AEBIOM A Biogas Road Map for Europe. AEBIOM, Brussels, Belgium. See http://www.seai.ie/Renewables/AD_In_Ireland_22nd_October/A_ Biogas_Roadmap_for_Europe.pdf (accessed 16/08/2017).

Al Seadi T, Drosg B, Fuchs W, Rutz D and Janssen R (2013) Biogas digestate quality and utilization. In The Biogas Handbook: Science, Production and Applications, 1st edn (Wellinger A, Murphy J and Baxter D (eds)). Woodhead Publishing, Cambridge, UK, pp. 267-301.

Antonini S, Paris S, Eichert T and Clemens J (2011) Nitrogen and phosphorus recovery from human urine by struvite precipitation and air stripping in Vietnam. CLEAN - Soil, Air, Water 39(12): 1099-1104.

Ayala-Parra P, Liu Y, Field JA and Sierra-Alvarez R (2017) Nutrient recovery and biogas generation from the anaerobic digestion of waste biomass from algal biofuel production. Renewable Energy 108: $410-416$

Boehler MA, Heisele A, Seyfried A, Gromping $M$ and Siegrist $H$ (2015) $\left(\mathrm{NH}_{4}\right)_{2} \mathrm{SO}_{4}$ recovery from liquid side streams. Environmental Science and Pollution Research International 22(10) 7295-7305.

Bonmatí A and Flotats X (2003a) Pig slurry concentration by vacuum evaporation: influence of previous mesophilic anaerobic digestion process. Journal of the Air and Waste Management Association 53(1): 21-31.

Bonmatí A and Flotats X (2003b) Air stripping of ammonia from pig slurry: characterisation and feasibility as a pre- or post-treatment to mesophilic anaerobic digestion. Waste Management 23(3) 261-272.

Bright A, Bulson H, Henderson A et al. (2011) An Introduction to the Production of Biomethane Gas and Injection to the National Gas Grid. Organic Resource Agency Ltd, Malvern, UK. See http://www.wrap.org.uk/sites/files/wrap/AWM\%20Biomethane $\%$ 20 to $\% 20$ Grid $\% 2005 \% 2007 \% 2011$.pdf (accessed 16/08/2017).

Cherubini F (2010) The biorefinery concept: using biomass instead of oil for producing energy and chemicals. Energy Conversion and Management 51(7): 1412-1421.

Chiumenti A, da Borso F, Chiumenti R, Teri F and Segantin P (2013) Treatment of digestate from a co-digestion biogas plant by means of vacuum evaporation: tests for process optimization and environmental sustainability. Waste Management 33(6): 1339-1344.

Choudhary VR, Mondal KC and Choudhary TV (2006) Partial oxidation of methane to syngas with or without simultaneous steam or $\mathrm{CO}_{2}$ reforming over a high-temperature stable- $\mathrm{NiCoMgCeO}_{\mathrm{x}}$ supported on zirconia-hafnia catalyst. Applied Catalysis A: General 306: 45-50.

Deal C, Brewer CE, Brown RC, Okure MAE and Amoding A (2012) Comparison of kiln-derived and gasifier-derived biochars as soil amendments in the humid tropics. Biomass and Bioenergy 37: 161-168.

Dias BO, Silva CA, Higashikawa FS, Roig A and Sanchez-Monedero MA (2010) Use of biochar as bulking agent for the composting of poultry manure: effect on organic matter degradation and humification. Bioresource Technology 101(4) 1239-1246.

Drosg B, Fuchs W, Al Seadi T, Madsen M and Linke B (2015) Nutrient Recovery by Biogas Digestate Processing (Baxter D (ed.)). IEA Bioenergy, Paris, France. See http://www.ieabiogas.net/files/daten-redaktion/download/Technical $\%$ 20Brochures/NUTRIENT_RECOVERY_RZ_web1.pdf (accessed 16/08/2017).

EA and WRAP (Environment Agency and Waste \& Resources Action Programme) (2009) Anaerobic Digestate: End of Waste Criteria for the Production and Use of Quality Outputs from Anaerobic Digestion of Source-Segregated Biodegradable Waste. EA, Rotherham, UK and WRAP, Banbury, UK. See https://www.gov. uk/government/publications/quality-protocol-anaerobic-digestate (accessed 16/08/2017).

Flotats X, Foged HL, Bonmati Blasi A et al. (2011) Manure Processing Technologies. Technical Report No. II concerning 'Manure Processing Activities in Europe' to the European Commission, Directorate-General Environment. Agro Business Park, Tjele, Denmark. See http://agro-technology-atlas.eu/docs/21010_ technical_report_II_manure processing technologies.pdf (accessed 16/08/2017)

Frost P and Gilkinson S (2011) 27 Months Performance Summary for Anaerobic Digestion of Dairy Cow Slurry at AFBI Hillsborough. 
AFBI, Hillsborough, UK. See https://www.scribd.com/document/ 250981915/FIRST-18-MONTH-PERFORMANCE-SUMMARYFOR-ANAEROBIC-DIGESTION-OF-DAIRY-COW-SLURRYAT-AFBI-HILLSBOROUGH (accessed 16/08/2017).

Gnansounou E and Kenthorai Raman J (2016) Life cycle assessment of algae biodiesel and its co-products. Applied Energy 161: 300-308.

Gold S and Seuring S (2011) Supply chain and logistics issues of bio-energy production. Journal of Cleaner Production 19(1): 32-42.

Groom E and Orozco A (2014) Northern Ireland Biogas Research Action Plan 2020. QUESTOR Centre, Queen's University of Belfast, Belfast, UK. See http://questor.qub.ac.uk/GeneralFileStorenew/ DO-Bioenergy/Filetoupload,465991,en.pdf (accessed 16/08/2017).

He LL, Zhong ZK and Yang HM (2017) Effects on soil quality of biochar and straw amendment in conjunction with chemical fertilizers. Journal of Integrative Agriculture 16(3): 704-712.

Holm-Nielsen JB, Al Seadi T and Oleskowicz-Popiel P (2009) The future of anaerobic digestion and biogas utilization. Bioresource Technology 100(22): 5478-5484.

IEA (International Energy Agency) (2015) 100\% Biogas for Urban Transport in Linköping, Sweden: Biogas in Buses, Cars And Trains. IEA, Paris, France, IEA Bioenergy Task 37.

Inyang $\mathrm{M}, \mathrm{Gao} \mathrm{B}$, Pullammanappallil $\mathrm{P}$, Ding $\mathrm{W}$ and Zimmerman $\mathrm{AR}$ (2010) Biochar from anaerobically digested sugarcane bagasse. Bioresource Technology 101(22): 8868-8872.

Kataki S, Hazarika S and Baruah DC (2017) Assessment of by-products of bioenergy systems (anaerobic digestion and gasification) as potential crop nutrient. Waste Management 59: 102-117.

Markou G and Georgakakis D (2011) Cultivation of filamentous cyanobacteria (blue-green algae) in agro-industrial wastes and wastewaters: a review. Applied Energy 88(10): 3389-3401.

Matsunaka T, Sawamoto T, Ishimura H, Takakura K and Takekawa A (2006) Efficient use of digested cattle slurry from biogas plant with respect to nitrogen recycling in grassland. International Congress Series 1293: 242-252.

Monlau F, Sambusiti C, Antoniou N, Barakat A and Zabaniotou A (2015) A new concept for enhancing energy recovery from agricultural residues by coupling anaerobic digestion and pyrolysis process. Applied Energy 148: 32-38.

Monlau F, Francavilla M, Sambusiti C et al. (2016) Toward a functional integration of anaerobic digestion and pyrolysis for a sustainable resource management. Comparison between solid-digestate and its derived pyrochar as soil amendment. Applied Energy 169: 652-662.

Monson KD, Esteves SR, Guwy AJ and Dinsdale RM (2007) Anaerobic Digestion of Biodegradable Municipal Wastes: A Review. Sustainable Environment Research Centre, Treforest, UK. See http://www.walesadcentre.org.uk/Controls/Document/Docs/ Anaerobic $\% 20$ Digestion $\% 20$ of $\% 20$ BMW $\% 20$ _compressed_\%20- $\%$ 20A\%20Review\%20_for\%20print_.pdf (accessed 05/09/2017).

Murphy F, Devlin G, Deverell R and McDonnell K (2014) Potential to increase indigenous biodiesel production to help meet 2020 targets - an EU perspective with a focus on Ireland. Renewable and Sustainable Energy Reviews 35: 154-170.

Pérez-Camacho MN, Abu-Dahrieh J, Goguet A, Sun K and Rooney D (2014) Self-cleaning perovskite type catalysts for the dry reforming of methane. Chinese Journal of Catalysis 35(8): 1337-1346.

Pérez-Camacho MN, Abu-Dahrieh J, Rooney D and Sun K (2015) Biogas reforming using renewable wind energy and induction heating. Catalysis Today 242(A): 129-138.

Piloto-Rodríguez R, Sánchez-Borroto Y, Melo-Espinosa EA and Verhelst S (2017) Assessment of diesel engine performance when fueled with biodiesel from algae and microalgae: an overview. Renewable and Sustainable Energy Reviews 69: 833-842.

Prajapati SK, Kumar P, Malik A and Vijay VK (2014) Bioconversion of algae to methane and subsequent utilization of digestate for algae cultivation: a closed loop bioenergy generation process. Bioresource Technology 158: 174-180.

Rawat I, Ranjith Kumar R, Mutanda T and Bux F (2011) Dual role of microalgae: phycoremediation of domestic wastewater and biomass production for sustainable biofuels production. Applied Energy 88(10): $3411-3424$

Sawatdeenarunat C, Nguyen D, Surendra KC et al. (2016) Anaerobic biorefinery: current status, challenges, and opportunities. Bioresource Technology 215: 304-313.

Slade R, Saunders R, Gross R and Bauen A (2011) Energy from Biomass: The Size of the Global Resource An Assessment of the Evidence that Biomass Can Make a Major Contribution to Future Global Energy Supply. UK Energy Research Centre, London, UK. See http://www.ukerc.ac.uk/publications/energy-from-biomass-the-sizeof-the-global-resource.html (accessed 16/08/2017).

Smyth BM, Murphy JD and O'Brien CM (2009) What is the energy balance of grass biomethane in Ireland and other temperate northern European climates? Renewable and Sustainable Energy Reviews 13(9): 2349-2360.

Smyth BM, Smyth H and Murphy JD (2010) Can grass biomethane be an economically viable biofuel for the farmer and the consumer? Biofuels, Bioproducts and Biorefining 4(5): $519-537$.

Stefaniuk M and Oleszczuk P (2015) Characterization of biochars produced from residues from biogas production. Journal of Analytical and Applied Pyrolysis 115: 157-165.

Svehla P, Radechovska H, Pacek L et al. (2017) Nitrification in a completely stirred tank reactor treating the liquid phase of digestate: the way towards rational use of nitrogen. Waste Management 64: 96-106.

Tampio E, Marttinen S and Rintala J (2016) Liquid fertilizer products from anaerobic digestion of food waste: mass, nutrient and energy balance of four digestate liquid treatment systems. Journal of Cleaner Production 125: 22-32.

Tani M, Sakamoto N, Kishimoto T and Umetsu K (2006) Utilization of anaerobically digested dairy slurry combined with other wastes following application to agricultural land. International Congress Series 1293: 331-334.

Uslu A, Faaij APC and Bergman PCA (2008) Pre-treatment technologies, and their effect on international bioenergy supply chain logistics. Techno-economic evaluation of torrefaction, fast pyrolysis and pelletisation. Energy 33(8): 1206-1223.

Vazquez-Rowe I, Golkowska K, Lebuf V et al. (2015) Environmental assessment of digestate treatment technologies using LCA methodology. Waste Management 43: 442-459.

Wang L, Li Y, Chen P et al. (2010) Anaerobic digested dairy manure as a nutrient supplement for cultivation of oil-rich green microalgae Chlorella sp. Bioresource Technology 101(8): 2623-2628.

WRAP (The Waste and Resources Action Programme) (2011) Digestates: Realising the Fertiliser Benefits for Crops and Grassland. WRAP, Banbury, UK. See http://www.wrap.org. $\mathrm{uk} /$ content/digestates-realising-fertiliser-benefits-crops-andgrassland-0. (accessed 16/08/2017)

WRAP (2012) Enhancement and Treatment of Digestates from Anaerobic Digestion. WRAP, Banbury, UK. See http://www.wrap. org.uk/sites/files/wrap/Digestates $\% 20$ from $\% 20$ Anaerobic $\%$ 20Digestion $\% 20 \mathrm{~A} \% 20$ review $\% 20$ of $\% 20$ enhancement $\%$ 20 techniques $\% 20$ and $\% 20$ novel $\% 20$ digestate $\% 20$ products_0.pdf (accessed 16/08/2017). 
WRAP (2014) PAS 110:2014 Specification for Whole Digestate, Separated Liquor and Separated Fibre Derived from the Anaerobic Digestion of Source-Segregated Biodegradable Materials.

WRAP, Banbury, UK. See https://static1.squarespace.com/static/ 56d1a94e1bbee09a4bc6c578/t/56d4ba502b8ddea29eb2872f/ 1456781906892/PAS110_2014_final.pdf (accessed 16/08/2017).

Xia A and Murphy JD (2016) Microalgal Cultivation in Treating Liquid Digestate from Biogas Systems. Trends in Biotechnology 34(4): 264-275.

Yao Y, Gao B, Inyang M et al. (2011) Biochar derived from anaerobically digested sugar beet tailings: characterization and phosphate removal potential. Bioresource Technology 102(10): 6273-6278.

Yliopisto J (2013) D5.1-Evaluation of Potential Technologies and Operational Scales Reflecting Market Needs for Low-cost Gas Upgrading Systems. VALORGAS: Valorisation of Food Waste to Biogas, Grant Agreement No.: 241334, Seventh Framework Programme Theme Energy: Biowaste as Feedstock for Second Generation. University of Southampton, Southampton, UK. See http://www.valorgas.soton.ac.uk/Deliverables/111129_

VALORGAS_241334_D5-1_Final_version.pdf (accessed 16/08/2017).

\section{How can you contribute?}

To discuss this paper, please email up to 500 words to the editor at journals@ice.org.uk. Your contribution will be forwarded to the author(s) for a reply and, if considered appropriate by the editorial board, it will be published as discussion in a future issue of the journal.

Proceedings journals rely entirely on contributions from the civil engineering profession (and allied disciplines).

Information about how to submit your paper online is available at www.icevirtuallibrary.com/page/authors, where you will also find detailed author guidelines. 